\title{
Cationic congeners captured
}

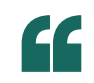

when we

instead

treated $\left[\mathrm{Cl}_{3} \mathrm{E}\right]^{+}$ with $\mathrm{P}_{4}$ we got a substitution reaction that delivered the $\left[\mathrm{P}_{3} \mathrm{E}\right]^{+}$target

the gas phase. A team led by Ingo Krossing has now addressed this by describing in Chemical Science the solution-phase generation and NMR characterization of three cationic congeners $\left[\mathrm{P}_{3} \mathrm{E}\right]^{+}(\mathrm{E}=\mathrm{S}, \mathrm{Se}, \mathrm{Te})$.

An early glimpse of heteroatomic tetrahedral cations came almost half a century ago with the observation of $\left[\mathrm{Pn}_{3} \mathrm{E}\right]^{+}(\mathrm{Pn}=\mathrm{P}, \mathrm{As} ; \mathrm{E}=\mathrm{S}, \mathrm{Se})$



as fragment ions in mass spectra of $\mathrm{Pn}_{4} \mathrm{E}_{3}$. These ions, which can be viewed as group 15 tetrahedra in which one atom is replaced with a group 16 cation, were rediscovered by Krossing's team in mass spectra of $\mathrm{Ag}^{+}-\mathrm{P}_{4} \mathrm{E}_{3}$ mixtures. This prompted the team to find a scalable and rational synthesis of $\left[\mathrm{P}_{3} \mathrm{E}\right]^{+}(\mathrm{E}=\mathrm{S}, \mathrm{Se}, \mathrm{Te})$, which necessitated the $\mathrm{E}^{\mathrm{IV}}$ cations $\left[\mathrm{Cl}_{3} \mathrm{E}\right]^{+}$as precursors. These strong electrophiles are only compatible with weakly coordinating anions such as the aluminates the team had previously developed. The aluminates are suitably 'inert' and their salts are soluble in $\mathrm{CH}_{2} \mathrm{Cl}_{2}$, a good solvent for nucleophiles such as $\left[\mathrm{Nb}(\mathrm{OAr})_{3}\left(\mathrm{P}_{3}\right)\right]^{-}-$the source of $\mathrm{P}_{3}{ }^{3-}$ that had previously been combined with $\mathrm{Cl}_{3} \mathrm{As}$ to prepare $\mathrm{P}_{3}$ As. "The $\left[\mathrm{Nb}(\mathrm{OAr})_{3}\left(\mathrm{P}_{3}\right)\right]^{-}$reagent got chlorinated by $\left[\mathrm{Cl}_{3} \mathrm{E}\right]^{+}$to give $\mathrm{PCl}_{3}$, but when we instead treated $\left[\mathrm{Cl}_{3} \mathrm{E}\right]^{+}$with $\mathrm{P}_{4}$ we got a substitution reaction that delivered the $\left[\mathrm{P}_{3} \mathrm{E}\right]^{+}$target and $\mathrm{Cl}_{3} \mathrm{P}$ as major products." Having generated their $\left[\mathrm{P}_{3} \mathrm{E}\right]^{+}$tetrahedra, Krossing and colleagues found that their ${ }^{31} \mathrm{P}$ NMR resonances follow the trend $\mathrm{P}_{4}<\left[\mathrm{P}_{3} \mathrm{~S}\right]^{+}<\left[\mathrm{P}_{3} \mathrm{Se}\right]$ $<\left[\mathrm{P}_{3} \mathrm{Te}\right]^{+}$, with the latter two ions giving rise to unusually high ${ }^{77} \mathrm{Se}$ and ${ }^{125} \mathrm{Te}$ chemical shifts for $\mathrm{E}^{\mathrm{IV}}$ species. The team rationalized these shifts in terms of resonance structures in which chalcogen cations $\mathrm{E}^{4+}$ are magnetically shielded by aromatic $\mathrm{P}_{3}{ }^{3-}$ rings. This model is consistent with the large and negative nuclear-independent chemical shifts calculated for the tetrahedra — values that are diagnostic of aromaticity at the centre of a cluster. In this regard, the new cations are similar to $\mathrm{P}_{4}$, which does not have six 2-centre 2-electron bonds and four lone pairs but instead has a more delocalized electronic structure, as evidenced by $\mathrm{P}_{4}$ undergoing protonation at its edges rather than its vertices. The four tetrahedra have similar frontier molecular orbitals, although those calculated for $\left[\mathrm{P}_{3} \mathrm{E}\right]^{+}$ lie at lower energies than those for $\mathrm{P}_{4}$ on account of charge, and there is some lifting of degeneracy on shifting from $T_{d}$ to $C_{3 v}$ symmetry. The differences between $\mathrm{P}_{4}$ and $\left[\mathrm{P}_{3} \mathrm{E}\right]^{+}$are more marked when it comes to reactivity - the cations are potent electrophiles with large calculated $\mathrm{F}^{-}$affinities, so it is not surprising that they had eluded synthesis for so long.

Despite these encouraging results, the story of $\left[\mathrm{P}_{3} \mathrm{E}\right]^{+}$continues to be written. Indeed, Krossing's team got $\left[\mathrm{P}_{3} \mathrm{E}\right]^{+}$and $\mathrm{Cl}_{3} \mathrm{P}$ but could not isolate the former as a salt because of a competing reaction that affords $\left[\mathrm{Cl}_{2} \mathrm{P}_{5}\right]^{+}$and $\mathrm{Cl}_{2} \mathrm{E}_{2}$. The team is on the lookout for more selective synthetic routes, including the replacement of $\left[\mathrm{Cl}_{3} \mathrm{E}\right]^{+}$with $\left[\mathrm{F}_{3} \mathrm{E}\right]^{+}$, even stronger electrophiles that would afford $\left[\mathrm{P}_{3} \mathrm{E}\right]^{+}$along with volatile and easily removable $\mathrm{F}_{3} \mathrm{P}$. As is so often the case with reactive cations, the challenge here would be to find suitable anions. For example, the anions for which $\left[\mathrm{F}_{3} \mathrm{E}\right]^{+}$salts are known are incompatible with the $\left[\mathrm{P}_{3} \mathrm{E}\right]^{+}$target. "We do have ideas to continue and are working on this, but this is difficult chemistry and will take some time," anticipates Krossing.

David Schilter

ORIGINAL ARTICLE Weis, P. et al. First experimental evidence for the elusive tetrahedral cations $\left[\mathrm{EP}_{3}\right]^{+}(\mathrm{E}=\mathrm{S}, \mathrm{Se}$, Te) in the condensed phase. Chem. Sci. https://doi.org/10.1039/C9SC03915E (2019) 